\title{
Comparison of Liposomal Bupivacaine for Pain Management after Immediate and Delayed Deep Inferior Epigastric Perforator Free Flap Reconstruction
}

\author{
Rebecca Knackstedt*, James Gatherwright, Amir Ghaznavi, Steven Bernard, Graham Schwarz, \\ Andrea Moreira, Raffi Gurunluoglu and Risal Djohan
}

Cleveland Clinic Foundation, Cleveland, Ohio, United States

*Corresponding author: Knackstedt R, Cleveland Clinic Foundation, Cleveland, Ohio, United States, Tel: 216-387-0287; E-mail: knacksr@ccf.org

Citation: Knackstedt R, Gatherwright J, Ghaznavi A, Bernard S, Schwarz G, et al. (2018) Comparison of Liposomal Bupivacaine For Pain Management after Immediate and Delayed Deep Inferior Epigastric Perforator Free Flap Reconstruction. J Aesthet Reconstr Surg. Vol 4 No.1: 5

Received date: March 19, 201 8; Accepted date: March 28, 2018; Published date: April 4, 2018

Copyright: @ 2018 Knackstedt R, et al. This is an open-access article distributed under the terms of the Creative Commons Attribution License, which permits unrestricted use, distribution, and reproduction in any medium, provided the original author and source are credited.

\section{Abstract}

Patient analgesia can be addressed pre, intra and postoperatively. The utilization of local anesthetics administered intra-operatively is limited by the medication's short duration of action. However, an intraoperative transversus abdominis plane (TAP) block can be utilized to anesthetize the T6-L1 intercostal nerves that supply the anterior abdominal wall. This provides analgesia to the abdominal wall, which has been identified as the largest source of post-operative pain following abdominally-based autologous tissue breast reconstruction.

Keywords: Patient; Analgesia; Abdominal wall; Breast reconstruction

\section{Introduction}

We recently demonstrated in a prospective, randomized, control trial that a liposomal bupivacaine TAP block in patients undergoing delayed unilateral deep inferior epigastric perforator (DIEP) reconstruction resulted in decreased postoperative narcotic utilization as compared to a bupivacaine TAP block, pain cathether or local infiltration [1-8]. We were able to demonstrate also, via a retrospective chart review, that these findings were upheld in patients who underwent bilateral delayed reconstruction [9]. The goal of this retrospective analysis was to compare narcotic usage and length of stay in patients who underwent delayed versus immediate unilateral and bilateral DIEP reconstruction and received a liposomal bupivacaine TAP block.

\section{Methods}

\section{Patient selection}

IRB approval was granted for this retrospective chart review. Patients were eligible for inclusion if they had undergone immediate or delayed, unilateral or bilateral DIEP reconstruction for breast cancer by any staff in the Department of Plastic and Reconstructive Surgery at our Institution from 2015-2017 and received a TAP block with liposomal bupivacaine. Delayed reconstruction was performed with tissue expander placement at time of mastectomy with autologous tissue transfer performed at a later date. Immediate reconstruction was autologous tissue transfer performed at time of mastectomy. Charts were reviewed for patient demographics and oncologic history.

\section{Endpoints}

The primary endpoint was total postoperative intravenous and oral narcotic utilization until 72 hours after surgery or discharge, whatever time point came first. Any pain medications were converted to morphine equivalents. Length of stay was also recorded.

\section{Interventions}

All patients were treated with a liposomal bupivacaine TAP block. The correct plane of injection for the TAP block was determined via ultrasound intra-operatively. $266 \mathrm{mg}$ of liposomal bupivicaine was diluted in $60 \mathrm{~mL}$ along with $20 \mathrm{cc}$ of $0.25 \%$ bupivacaine. A 25 -gauge needle was used to deliver the medication. The infiltration technique consisted of $2 / 3$ of the mixture utilized as the TAP block and the other $1 / 3$ of the mixture infiltrated into the operative breast(s). All patients had two closed-suction drains placed at the inferior aspect of the donor site, oriented horizontally. 


\section{Statistical analysis}

Comparisons were made between patients who underwent unilateral or bilateral delayed versus immediate reconstruction. Statistical analysis was performed using SPSS (Chicago, IL, USA; IBM Corp). Parametric data was analyzed using multivariate analysis and student's t-test for group and inter-group differences. Non-parametric data was similarly analyzed using Kruskall-Wallis and Mann-Whitney $U$ tests. Significance was defined as a $p$-value less than or equal to 0.05 .

Table 1 Patient demographics.

\section{Results}

\section{Patient demographics}

22 patients fit inclusion criteria for this study. There were 9 , 4, 6 and 6 patients in the unilateral delayed and unilateral immediate, bilateral delayed and bilateral immediate cohorts, respectively. The patient cohorts were well matched with no statistical differences between age and BMI (Table 1). The average ages for the bilateral immediate and delayed groups were 51.2 and 49.2 , respectively $(p=0.5)$.

\begin{tabular}{|l|l|l|l|l|l|l|}
\hline Demographic & Unilateral delayed & Unilateral immediate & $\mathbf{p}$-value & Bilateral delayed & Bilateral immediate & $\mathbf{p}$-value \\
\hline Number of patients & 9 & 4 & $\mathrm{n} / \mathrm{a}$ & 6 & 6 & $\mathrm{n} / \mathrm{a}$ \\
\hline Age (years) & 47.1 & 56.5 & 0.48 & 49.2 & 51.2 & 0.05 \\
\hline BMI & 30.4 & 26.2 & 0.94 & 28.1 & 32.1 & 0.07 \\
\hline
\end{tabular}

The average BMI for the bilateral immediate and delayed groups were, 32.1 and 28.1 respectively $(p=0.69)$. The average ages for the unilateral immediate and delayed groups were 56.5 and 47.1, respectively ( $p=0.48$ ). The average BMI for the unilateral immediate and delayed groups were 26.2 and 30.4, respectively $(p=0.94)$.

\section{Length of stay}

The average length of stay for both bilateral cohorts was 4 days $(p=1)$. The average length of stay for the unilateral immediate and delayed groups were 3.75 and 3.3 , respectively $(p=0.75)$.

\section{Narcotic utilization (mg)}

Average total intravenous (IV) narcotic utilization was 56.2 and $23.3 \mathrm{mg}$ for the unilateral immediate and delayed groups, respectively $(p=0.04)$. Average total oral narcotic utilization was 21 and $28.4 \mathrm{mg}$ for the unilateral immediate and delayed groups, respectively $(p=0.3)$. Average total narcotic utilization was 77.2 and $50.7 \mathrm{mg}$ for the unilateral immediate and delayed groups, respectively ( $p=0.03$ ) (Figure 1).

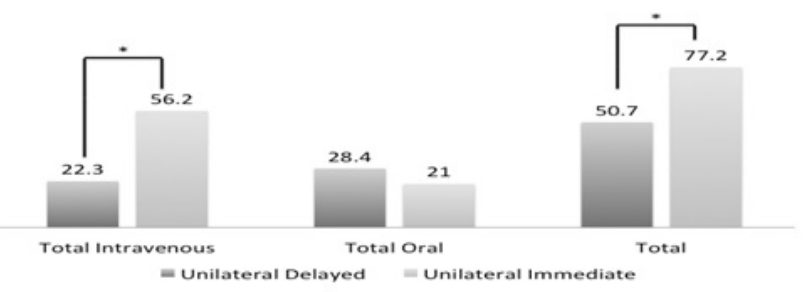

Figure 1 Total mg morphine utilized per unilateral group There was a statistically significant reduction in intravenous (IV) and total narcotics utilized by the unilateral delayed as compared to unilateral immediate group ( $p=0.04$ and 0.03 ).
Average total intravenous (IV) narcotic utilization was 89.5 and $71.9 \mathrm{mg}$ for the bilateral immediate and delayed groups, respectively $(p=0.25)$. Average total oral narcotic utilization was 37.8 and $33.8 \mathrm{mg}$ for the bilateral immediate and delayed groups, respectively $(p=0.24)$. Average total narcotic utilization was 127.3 and $105.6 \mathrm{mg}$ for the bilateral immediate and delayed groups, respectively ( $p=0.66$ ) (Figure 2).

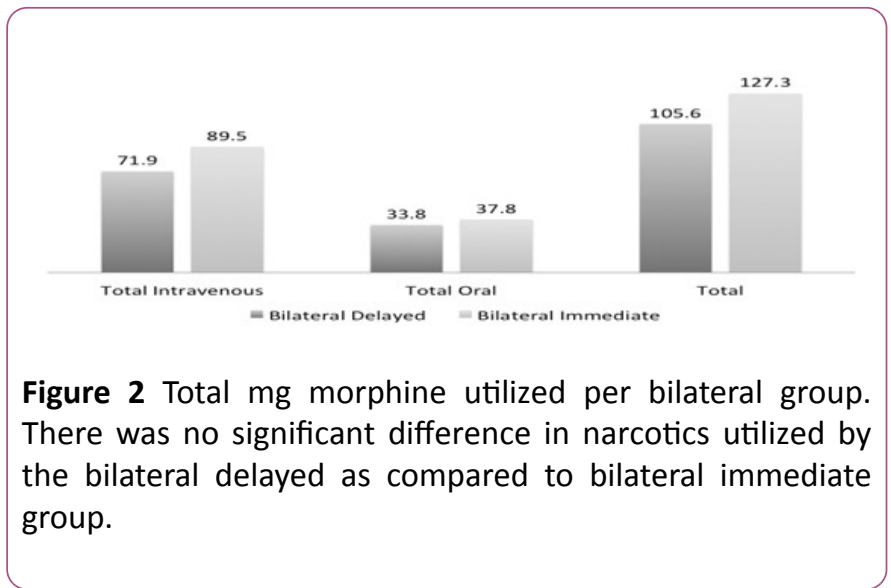

\section{Narcotic utilization $(\mathrm{mg} / \mathrm{kg} /$ day)}

Average total intravenous (IV) narcotic utilization was 0.25 and $0.11 \mathrm{mg} / \mathrm{kg} /$ day for the unilateral immediate and delayed groups, respectively $(p=0.04)$. Average total oral narcotic utilization was 0.09 and $0.13 \mathrm{mg} / \mathrm{kg} /$ day for the unilateral immediate and delayed groups, respectively $(p=0.3)$. Average total narcotic utilization was 0.19 and $0.12 \mathrm{mg} / \mathrm{kg} /$ day for the unilateral immediate and delayed groups, respectively $(p=0.02)$ (Figure 3). 


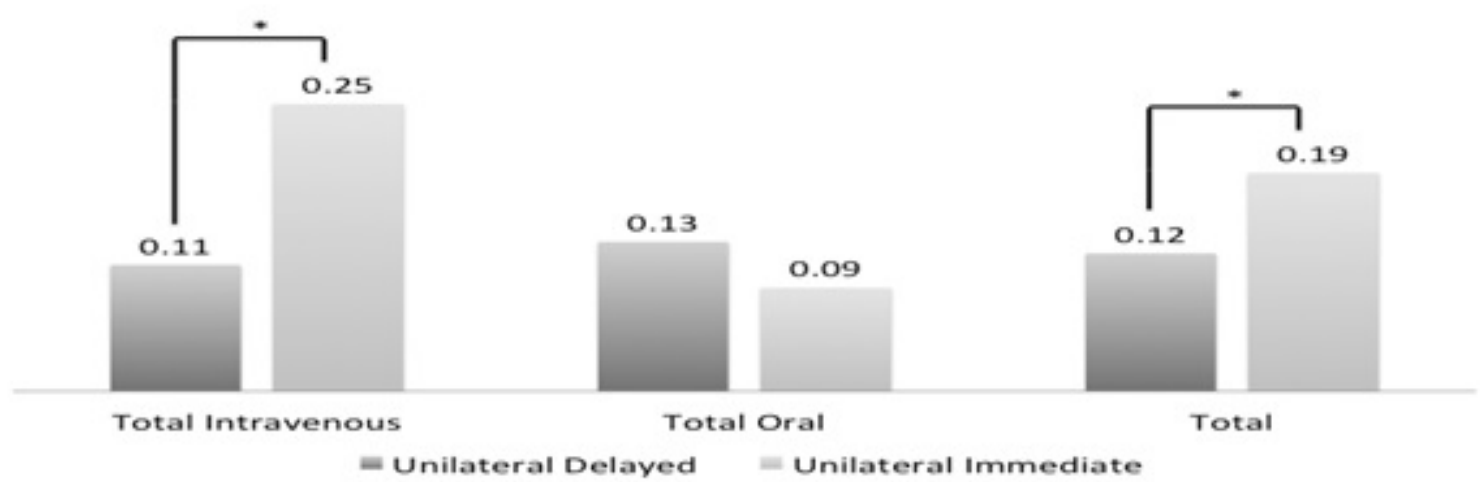

Figure 3 Total $\mathrm{mg}$ morphine in $\mathrm{mg} / \mathrm{kg} /$ day utilized per unilateral group. There was a statistically significant reduction in intravenous (IV) and total narcotics utilized by the unilateral delayed as compared to unilateral immediate group ( $p=0.04$ and 0.02).

Average total intravenous (IV) narcotic utilization was 0.32 and $0.31 \mathrm{mg} / \mathrm{kg} /$ day for the bilateral immediate and delayed groups, respectively $(p=0.21)$. Average total oral narcotic utilization was 0.14 and $0.15 \mathrm{mg} / \mathrm{kg} /$ day for the bilateral immediate and delayed groups, respectively $(p=0.15)$. Average total narcotic utilization was 0.23 and $0.23 \mathrm{mg} / \mathrm{kg} / \mathrm{day}$ for the bilateral immediate and delayed groups, respectively $(p=0.78)$ (Figure 4).

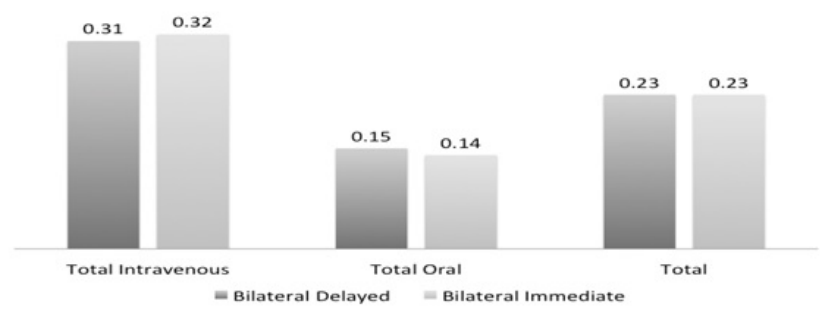

Figure 4 Total $\mathrm{mg}$ morphine in $\mathrm{mg} / \mathrm{kg} /$ day utilized per bilateral group. There was no significant difference in narcotics utilized by the bilateral delayed as compared to bilateral immediate group.

\section{Discussion}

The importance of post-operative pain control cannot be over emphasized. Appropriate pain control allows for quicker patient mobilization, improved patient satisfaction and decreased hospital stays and costs. For women undergoing abdominally-based autologous breast reconstruction, it has been demonstrated that a substantial component of the pain experienced post-operatively originates in the abdomen $[6,7]$. Therefore, addressing this source of pain could significantly improve overall post-operative pain control. A TAP block targets the T6-L1 intercostal nerves that supply the anterior abdominal wall [2-5] and thus, addresses the area of significant pain origination.
We have previously demonstrated in a prospective, randomized, control trial that a liposomal bupivacaine TAP block in patients undergoing delayed unilateral DIEP reconstruction resulted in decreased post-operative narcotic utilization as compared to bupivacaine TAP block, pain cathether or local infiltration [8]. We demonstrated in a retrospective study that these findings were upheld in patients who underwent bilateral delayed reconstruction [9]. In this retrospective review where all patients received a liposomal bupivicaine TAP block, we were able to demonstrate a significant reduction in narcotic utilization in women undergoing unilateral delayed as compared to immediate reconstruction. Women who underwent delayed reconstruction had tissue expanders previously placed at time of mastectomy. Thus, many nerves supplying the breast tissue and overlying skin were severed at time of mastectomy and the breast skin had been stretched and likely desensitized, prior to autologous reconstruction. Thus, for women undergoing delayed reconstruction, it is likely that even a larger component of their pain originates in the abdomen as compared to women who undergo immediate reconstruction and are faced with abdominal and breast pain. We were unable to demonstrate any difference in narcotic utilization when comparing the bilateral delayed and immediate cohorts. We hypothesize that this is due to the overwhelming pain originating from the breast that still requires significant narcotic usage. There was no difference in length of stay between the cohorts. This is not surprising as the length of stay for these patients typically ranges from three to five days and our study was not powered to detect small differences.

As women who underwent unilateral immediate reconstruction required more pain medication than those undergoing delayed reconstruction, this suggests that while the liposomal bupivicaine TAP block provides durable pain control in the abdomen, there is a yet to be addressed pain source originating in the breast. We typically employ local infusion to the breast tissue with liposomal bupivicaine, however, this is a non-specific approach. Alternatively, targeted infusions could be performed with paraverterbal, 
pectoralis or serratus anterior nerve blocks. This has shown promise in reducing post-operative mastectomy pain $[10,11]$ however, to our knowledge, this has not been explored in women undergoing autologous reconstruction or investigated in concert with a TAP block.

Our study is not without limitations. This was a retrospective chart review and analysis was limited to patients who had previously undergone reconstruction, resulting in a somewhat small sample size. This was a single institution study with multiple staff surgeons participating. Although the liposomal bupivacaine was diluted per recommendations and standardized across all surgeons, the same staff member did not inject it. This could have resulted in some variability in amount of medication injected at each site.

In conclusion, we have previously demonstrated a significant reduction in IV and total narcotic utilization when a liposomal bupivacaine TAP block was utilized in women undergoing unilateral and bilateral delayed DIEP reconstruction as compared to a bupivacaine TAP block, pain catheter or local infusion. We now demonstrate that a liposomal bupivicaine TAP block is more efficacious in reducing post-operative narcotic requirements in women undergoing unilateral delayed as compared to immediate DIEP reconstruction. However, we were unable to demonstrate any difference in post-operative narcotic requirements between bilateral delayed and immediate patients. Future, prospective studies are needed to prospectively investigate the effect that liposomal bupivacaine could have on simultaneously reducing pain originating in the breast to provide optimal pain control.

\section{References}

1. Vyas KS, Rajendran S, Morrison SD (2016) Systematic Review of Liposomal Bupivacaine (Exparel) for Postoperative Analgesia. Plast Reconstr Surg 138: 748e-756e.
2. Petersen PL, Mathiesen O, Torup H (2010) The transversus abdominis plane block: a valuable option for postoperative analgesia? A topical review. Acta Anaesthesiol Scand 54: 529-535.

3. Rafi AN (2001) Abdominal field block: a new approach via the lumbar triangle. Anaesthesia 56: 1024-1026.

4. Dierking GW, Dahl JB, Kanstrup J (1992) Effect of pre- vs. postoperative inguinal field block on postoperative pain after herniorrhaphy. Br J Anaesth 68: 344-348.

5. Kuppuvelumani P, Jaradi H, Delilkan A (1993) Abdominal nerve blockade for postoperative analgesia after caesarean section. Asia Oceania J Obstet Gynaecol 19: 165-169.

6. Albornoz CR, Bach PB, Pusic AL (2012) The influence of sociodemographic factors and hospital characteristics on the method of breast reconstruction, including microsurgery: a U.S. population-based study. Plast Reconstr Surg 129: 1071-1079.

7. Cordeiro PG (2008) Breast reconstruction after surgery for breast cancer. N Engl J Med 359: 1590-1601.

8. Gatherwright J, Knackstedt R, Ghaznavi A (2017) Prospective, Randomized, Controlled Comparison of Bupivacaine versus Liposomal Bupivacaine For Pain Management After Unilateral Delayed Deep Inferior Epigastric Perforator Free Flap Reconstruction. Plast Reconstr Surg.

9. Knackstedt R, Gatherwright J, Ghaznavi A (2017) Comparison of local anesthetic infusion pump bupivacaine versus transversus abdominis plane (TAP) block liposomal bupivacaine for pain management after bilateral deep inferior epigastric perforator free flap reconstruction. J Plast Reconstr Aesthet Surg.

10. Schnabel A, Reichl SU, Kranke P (2010) Efficacy and safety of paravertebral blocks in breast surgery: a meta-analysis of randomized controlled trials. Br J Anaesth 105: 842-852.

11. Kulhari S, Bharti N, Bala I (2016) Efficacy of pectoral nerve block versus thoracic paravertebral block for postoperative analgesia after radical mastectomy: a randomized controlled trial. $\mathrm{Br} \mathrm{J}$ Anaesth 117: 382-383. 